\title{
RANCANG BANGUN KENDALI SEKUEN UNTUK SAMBUNGAN JALA-JALA LISTRIK MENGGUNAKAN CYCLOCONVERTER
}

\author{
Yuliadi Erdani, Aris Eko Setiyawan, Maulana Aria Pratama \\ Jurusan Teknik Otomasi Manufaktur dan Mekatronika - Politeknik Manufaktur Negeri Bandung \\ Jl. Kanayakan No. 21 Bandung \\ Jawa Barat 40275, Indonesia \\ yul_erdani@yahoo.com; yul_erdani@polman-bandung.ac.id
}

Diterima: 27 Oktober 2010; Direvisi: 10 Desember 2010; Disetujui: 21 Desember 2010;

Terbit online: 24 Desember 2010.

\begin{abstract}
Abstrak
Rangkaian cycloconverter yang dikembangkan pada penelitian ini mensimulasikan rangkaian koneksi ke jalajala listrik dua buah function generator sebagai pengganti sumber tegangan AC-nya. Function generator pertama digunakan sebagai pengganti gelombang masukan pembangkit PLN dengan referensi frekuensi $50 \mathrm{~Hz}$. Function generator kedua digunakan sebagai pengganti gelombang masukan pembangkit baru dengan referensi frekuensi mulai dari $10 \mathrm{~Hz}$ sampai dengan $90 \mathrm{~Hz}$. Dengan inisialisasi kondisi frekuensi seperti itu, maka dimungkinkan perubahan frekuensi berupa penaikkan frekuensi dari $10 \mathrm{~Hz}-40 \mathrm{~Hz}$ menjadi $50 \mathrm{~Hz}$ dan penurunan frekuensi dari $60 \mathrm{~Hz}-90 \mathrm{~Hz}$ menjadi $50 \mathrm{~Hz}$. Rangkaian cycloconverter ini menggunakan rangkaian trigger untuk mengaktifkan komponen elektronikanya. Rangkaian trigger tersebut meliputi rangkaian trigger penyulutan thyristor dan rangkaian trigger pengaktifan MOSFET. Semua perangkat keras pada rangkaian ini dikendalikan oleh mikrokontroler ATMega 8535 yang mengatur kerja dari rangkaian-rangkaian trigger yang dibutuhkan oleh cycloconverter. Hasil pengujian menunjukkan bahwa simulasi rangkaian cycloconverter ini dapat mengubah frekuensi, dan menyamakan sudut fasa pada jaringan listrik. Hal ini menunjukan bahwa cycloconverter yang dikembangkan memungkinkan untuk koneksi ke jala-jala listrik.
\end{abstract}

Kata kunci: cycloconverter, koneksi jala-jala listrik, elektronika daya.

\begin{abstract}
This developed cycloconverter circuit simulates grid connector circuit using two function generators, which substitute AC power. The first function generator was used to represent input wave from PLN with $50 \mathrm{~Hz}$ frequency. The other function generator was used to represent input wave from new generator with 10-90 Hz frequency. Such initial condition enabled us to control the frequency increase from $10 \mathrm{~Hz}-40 \mathrm{~Hz}$ to $50 \mathrm{~Hz}$ and decrease from $60 \mathrm{~Hz}-$ $90 \mathrm{~Hz}$ to $50 \mathrm{~Hz}$. This cycloconverter used trigger circuit to activate its electrical components. The trigger circuit contains trigger parts such as thyristor and MOSFET. All hardware components in this circuit were controlled by microcontroller ATMega 8535. This controller manages all trigger circuits that were needed by cycloconverter. The experiment result shows that the cycloconverter was able to modify frequency and phase angle, so that it enabled the connection to the electrical grid.
\end{abstract}

Key words: cycloconverter, electrical grid connection, power electronic.

\section{Pendahuluan}

Dikarenakan sumber daya listrik yang terbatas maka sering dilakukan pemadaman listrik secara bergilir oleh PLN sebagai perusahaan milik negara yang menyediakan energi listrik. Hal inilah yang membuat PLN membuka peluang bagi masyarakat Indonesia yang ingin membantu menambah daya listrik untuk memperbesar pendistribusian daya listrik.

Penambahan daya listrik PLN tersebut dapat dilakukan dengan cara memparalelkan jaringan listrik PLN dengan pembangkit listrik baru. Untuk dapat menghubungkan pembangkit listrik baru dengan sistem maka harus dilakukan sinkronisasi antara pembangkit listrik baru tersebut dengan PLN [1][2].
Syarat sinkronisasi adalah tegangan masukan dari pembangkit listrik baru harus sama dengan tegangan jaringan, frekuensi masukan dari pembangkit listrik baru harus sama dengan frekuensi jaringan, demikian juga dengan fasanya, pembangkit listrik baru dengan jaringan harus satu fasa. Oleh karena itu dibutuhkan sebuah alat untuk menghubungkan jaringan listrik PLN dengan pembangkit baru [1] [3] [4].

Tujuan makalah ini adalah untuk melaporkan hasil pembuatan rangkaian cycloconverter yang mensimulasikan rangkaian koneksi ke jala-jala listrik dengan menggunakan dua buah function generator sebagai pengganti sumber tegangan AC-nya. Function generator pertama digunakan sebagai pengganti gelombang masukan 
pembangkit PLN, sedangkan function generator kedua digunakan sebagai pengganti gelombang masukan pembangkit baru.

\section{ISI MAKALAH}

Untuk menunjang penelitian ini dibutuhkan peralatan berupa solder, alat ukur (osciloscope, voltmeter, frekuensi meter dan cycloconverter) dan peralatan mekanis untuk membuat penutup dari panelnya. Selain itu juga dibutuhkan perangkat lunak yang mempunyai kemampuan untuk membuat desain skematik rangkaian elektronika. Sedangkan bahannya berupa Printed Circuit Board (PCB) double layer, komponen Transistor-Transistor Logic (TTL berisi dioda, resistor, kapasitor, trimpot, dan lainnya), vertinax dan box cover.

Tahap persiapan meliputi pencarian data dan bahan mengenai cycloconverter dan data mengenai rangkaian trigger untuk cycloconverter, dilakukan dengan cara berselancar di internet, membaca buku literatur dan diskusi.

Pada bagian ini dijelaskan mengenai tahapan/proses pengembangan cycloconverter, terlihat pada Gambar 1. Tahap pertama peneliti melakukan analisis situasi yang bersumber dari lapangan dan literatur, dan mendefinisikan kebutuhan yang harus dipenuhi oleh sistem yang akan dibangun. Tahap berikutnya peneliti membuat perencanaan sistem berdasarkan hasil tahap sebelumnya. Selanjutnya peneliti menerjemahkan perencanaan system ke dalam konsep rancangan alat baik perangkat lunak maupun perangkat keras, yang di dalamnya diturunkan menjadi peralatan dan bahan serta perancangan peralatan itu sendiri. Tahap berikutnya adalah implementasi hasil rancangan dalam bentuk pembuatan alat. Di dalam proses pembuatan alat, senantiasa dilakukan uji coba parsial.

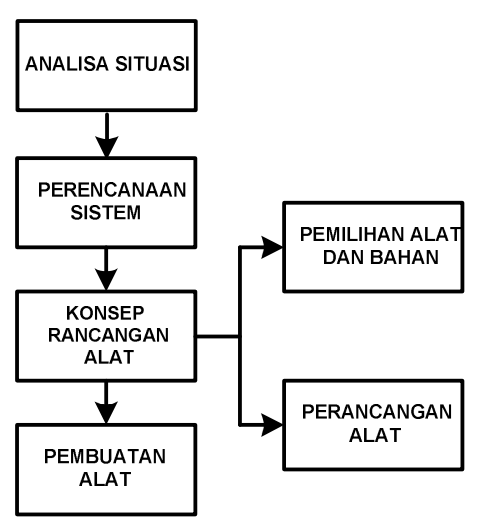

Gambar 1. Skema tahap-tahap proses perancangan.
Pada rancangan sistem untuk pembangkit baru menggunakan Regulator AC $50 \mathrm{~Hz}$ agar tegangan yang masuk ke dalam cycloconverter dapat dikontrol dan pembangkit lama menggunakan function generator (GFG-8219A, spesifikasi terlampir), sebagai referensi frekuensi $50 \mathrm{~Hz}$. Gambar 2 menunjukan arsitektur sistem yang dikembangkan.

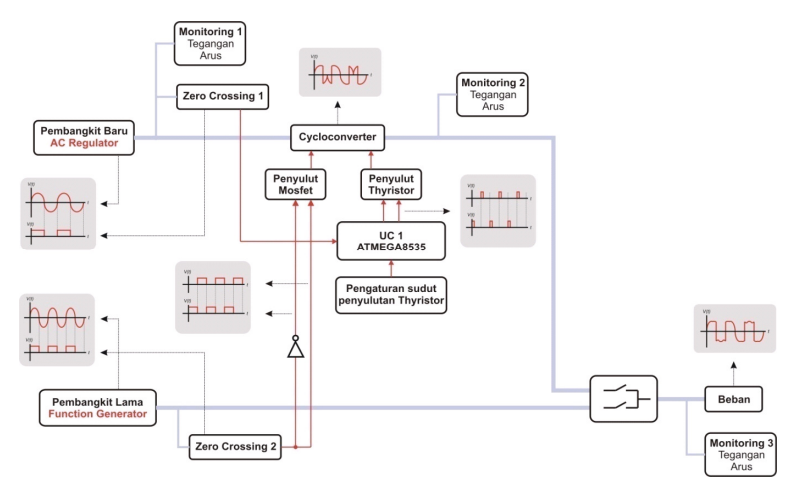

Gambar 2. Arsitektur sistem.

Agar keluaran tegangan keluaran dari cycloconverter dapat diatur maka digunakanlah thyristor bertipe 25RIA120. Hal yang dimanfaatkan dari thyristor ini adalah penyulutan tegangannya dimana besarnya tegangan yang disulut dapat diatur dengan mengatur sudut penyulutan dari Thyristor dari mikrokontroler.

Untuk mengatur besarnya frekuensi yang akan dihasilkan oleh cycloconverter maka digunakanlah Metal-Oxide-Semiconductor Field-Effect Transistor (MOSFET), dengan tipe IRF634. Hal yang dimanfaatkan dari MOSFET ini adalah waktu pengaktifan dari masing-masing MOSFET tersebut. Gambar 3 menunjukkan rangkain MOSFET dan thyristor dalam cycloconverter.

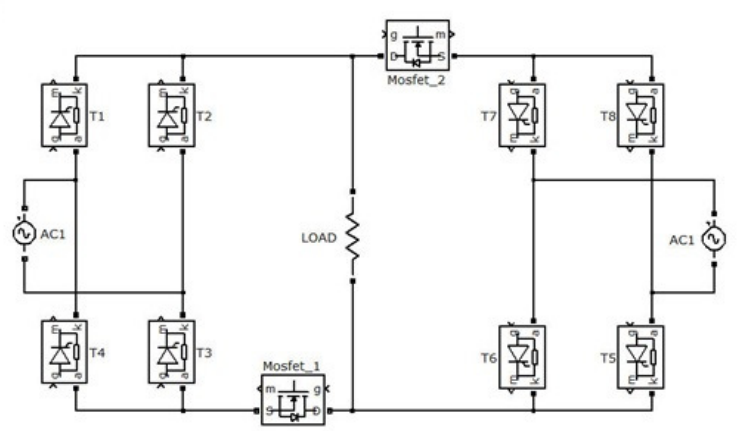

Gambar 3. Rangkaian cycloconverter menggunakan thyristor dan MOSFET.

Rangkaian cycloconverter terdiri dari dua buah rangkaian penyearah gelombang penuh dengan menggunakan thyristor. Satu rangkaian penyearah pertama berfungsi sebagai penghasil gelombang positif dan satu rangkaian lagi 
berfungsi sebagai penghasil gelombang negatif [6]. Besarnya waktu (dalam satuan ms) penyalaan antar kedua penyearah ini dapat mempengaruhi kerapatan suatu gelombang yang akan dihasilkan dan mengakibatkan terjadinya perubahan nilai dari frekuensi. Untuk itu digunakan MOSFET sebagai sakelar otomatis yang mengatur waktu pengaktifan dari kedua penyearah ini. thyristor yang digunakan pada pembuatan alat ini adalah thyristor bertipe 25RIA. Thyristor dapat mengurangi tegangan pada sebuah gelombang dengan mengatur sudut penyulutan thyristor itu sendiri [8]. Untuk mengatur sudut penyulutan thyristor tersebut, maka perlu dibuat sebuah rancangan rangkaian yang mampu memberikan trigger pada kaki gate dari thyristor yang berupa pulsa dengan keluaran arus yang mencukupi untuk men-trigger thyristor tersebut. Langkahlangkah atau bagaimana cara rangkaian cycloconverter ini bekerja dalam mengubah suatu frekuensi menjadi frekuensi yang baru sesuai dengan yang diinginkan, dapat dilihat pada [9].

Untuk men-trigger thyristor diperlukan gelombang pulsa dengan besar arus tertentu. Besar arus trigger thyristor tersebut bergantung pada spesifikasi dari thyristor yang digunakan, untuk rancangan ini thyristor yang digunakan bertipe 25RIA yang kaki gate-nya dapat ditrigger dengan minimal arus sebesar $60 \mathrm{~mA}$. Pembuatan rangkaian trigger thyristor ini menggunakan mikrokontroler sebagai pembangkit pulsa yang nantinya digunakan untuk mengatur sudut penyulutan pada thyristor, terlihat pada Gambar 4 . Arus keluaran mikrokontroler dikuatkan oleh $I C$ optocoupler LTV-4N35 [7]. Keluaran dari IC optocoupler ditempatkan pada kaki emitornya sehingga terjadi penguatan arus pada pulsa. Selain berfungsi sebagai penguat arus IC LTV4N35 tersebut berfungsi sebagai pengaman/isolator antara rangkaian elektronika dengan rangkaian mikrokontroler.

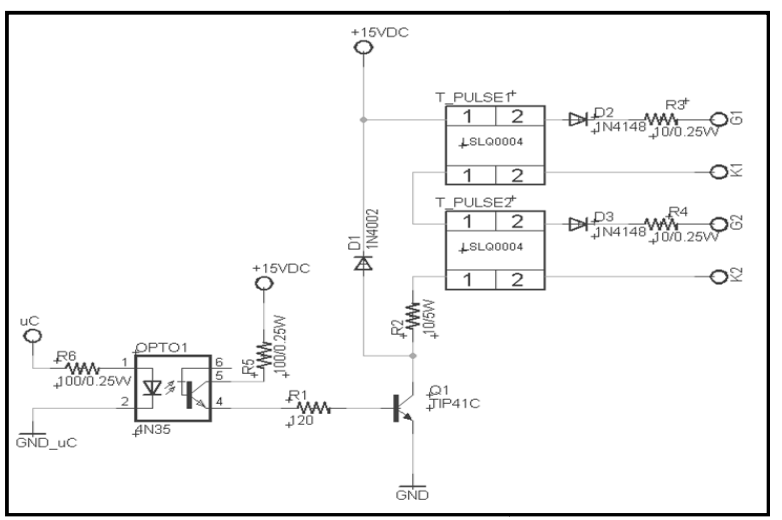

Gambar 4. Rangkaian penyulutan thyristor.

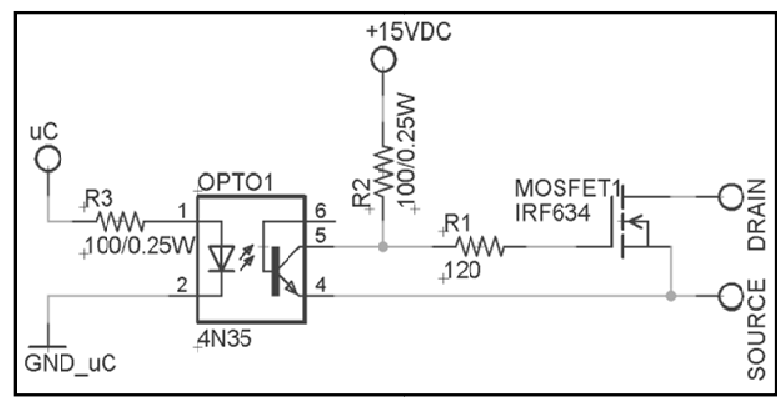

Gambar 5. Rangkaian trigger MOSFET.

Transistor TIP41C dalam rangkaian ini berfungsi sebagai sakelar otomatis yang menghubungkan antara rangkaian keluaran dari IC optocoupler dengan rangkaian trafo pulsa [7]. Transistor tipe TIP41C ini digunakan karena transistor ini telah terbukti tangguh di dunia robotika dan mikrokontroler, transistor ini sudah dibuktikan tangguh, baik sebagai sakelar otomatis maupun sebagai penguat. Hasil dari pengolahan pulsa yang dikeluarkan melalui trafo pulsa yang nantinya akan menjadi pulsa trigger penyulutan thyristor. Penggunaan trafo pulsa pada rangkaian ini juga berfungsi sebagai pengisolasi antara rangkaian elektronika dengan rangkaian elektronika daya sehingga ketika terjadi arus balik dari tegangan $\mathrm{AC}$ yang berlebih maka trafo pulsa saja yang akan rusak terlebih dahulu.

Berbeda dengan thyristor yang pada kaki gate-nya harus di-trigger dengan besar arus tertentu, maka untuk men-trigger MOSFET dapat dilakukan dengan memberikan tegangan dengan besar tertentu, terlihat pada Gambar 5. MOSFET yang digunakan pada rangkaian ini adalah MOSFET bertipe IRF634. Penggunaan MOSFET tipe IRF634 ini dilatarbelakangi karena tegangan masukan yang digunakan adalah sebesar 220 VAC dan tegangan (VDS) yang diberikan kepada Mosfer IRF634 ini maksimal 250 Volt. Tegangan maksimal untuk men-trigger MOSFET tipe IRF634 ini adalah \pm 20 Volt. Karena mikrokontroler hanya mampu memberikan tegangan keluaran sebesar \pm 5 volt maka dari itu pada rangkaian ini digunakanlah IC optocoupler LTV-4N35 dengan keluarannya ditempatkan pada kaki kolektor dari IC optocoupler tersebut. 


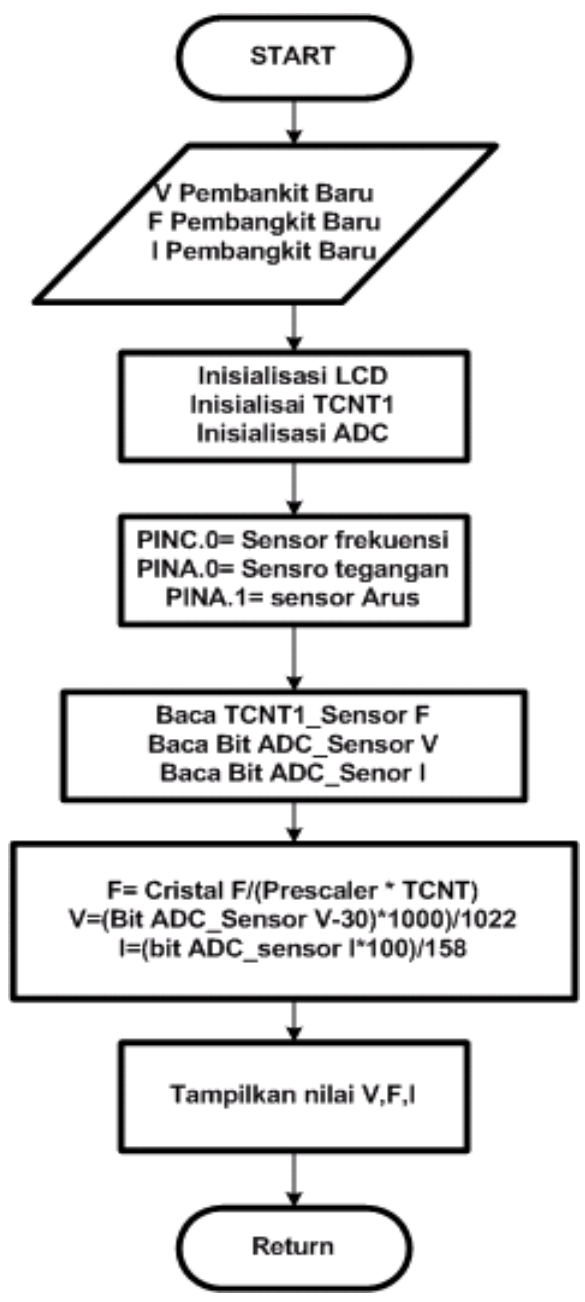

Gambar 6. Flowchart program minimum system.

Berbeda dengan perancangan rangkaian trigger penyulutan thyristor yang menggunakan kaki emitor sebagai keluaran tegangannya, IC optocoupler LTV-4N35 pada rangkaian ini berfungsi sebagai penguat tegangan maka dari itu keluaran dari IC optocoupler tersebut ditempatkan pada kaki kolektornya. Tegangan yang dikeluarkan IC optocoupler tersebut selalu mengikuti besar tegangan Vcc yang diberikan, apabila pada rangkaian diberikan tegangan (Vcc) sebesar +10 Volt maka keluarannya pun akan bernilai +10 Volt namun konsekuensinya bentuk pulsa keluarannya akan berkebalikan dengan bentuk pulsa awalnya, misalnya jika bentuk pulsa awal bernilai "1" (high) maka bentuk pulsa keluarannya akan bernilai "0" (low). Sama seperti penggunaan pada perancangan rangkaian trigger penyulutan thyristor, IC optocoupler LTV-4N35 selain berfungsi sebagai penguat tegangan pada rangkaian yang dibuat, IC inipun berfungsi sebagai isolator antara rangkaian mikrokontroler dengan rangkaian elektronika daya.

\section{Hasil \& Analisis Penelitian}

Pada pengujian rangkaian Cycloconverter ini besarnya tegangan pada pembangkit baru dan PLN berada pada besaran nilai yang sama. Frekuensi $50 \mathrm{~Hz}$ dijadikan referensi frekuensi untuk pembangkit PLN dan frekuensi $10 \mathrm{~Hz}$ sampai $90 \mathrm{~Hz}$ adalah frekuensi untuk pembangkit baru.

Dengan inisialisasi kondisi seperti itu, dilakukan penaikan frekuensi dari $10 \mathrm{~Hz}-40 \mathrm{~Hz}$ menjadi $50 \mathrm{~Hz}$ dan penurunan frekuensi dari $60 \mathrm{~Hz}-90 \mathrm{~Hz}$ menjadi $50 \mathrm{~Hz}$.

Untuk mengetahui kondisi awal dari nilai tegangan keluaran yang dihasilkan oleh cycloconverter maka fungsi dari thyristor digantikan oleh dioda. Hasilnya dapat dilihat pada Gambar 7 sampai dengan Gambar 10.

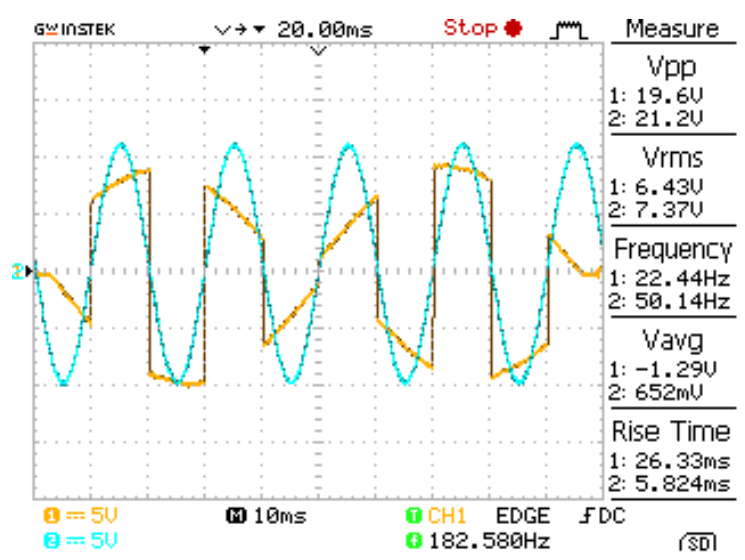

Gambar 7. Gelombang penaikan frekuensi dari $10 \mathrm{~Hz}$ menjadi $50 \mathrm{~Hz}$.

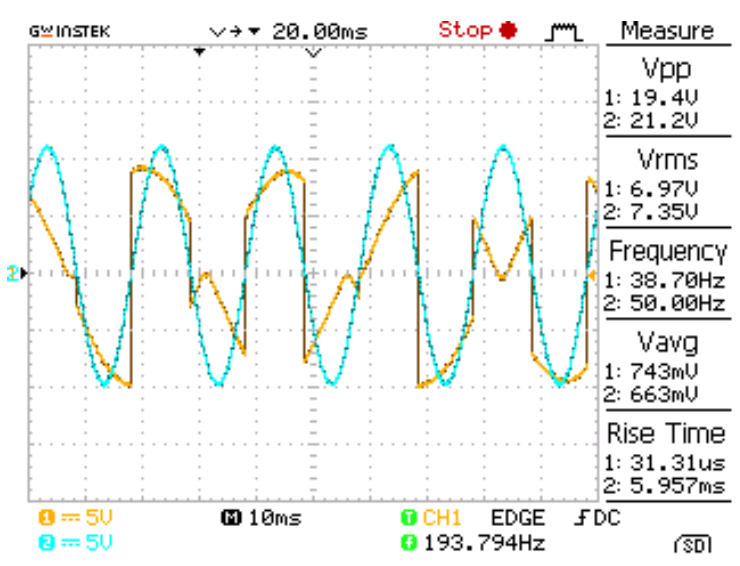

Gambar 8. Gelombang penaikan frekuensi dari $20 \mathrm{~Hz}$ menjadi $50 \mathrm{~Hz}$. 


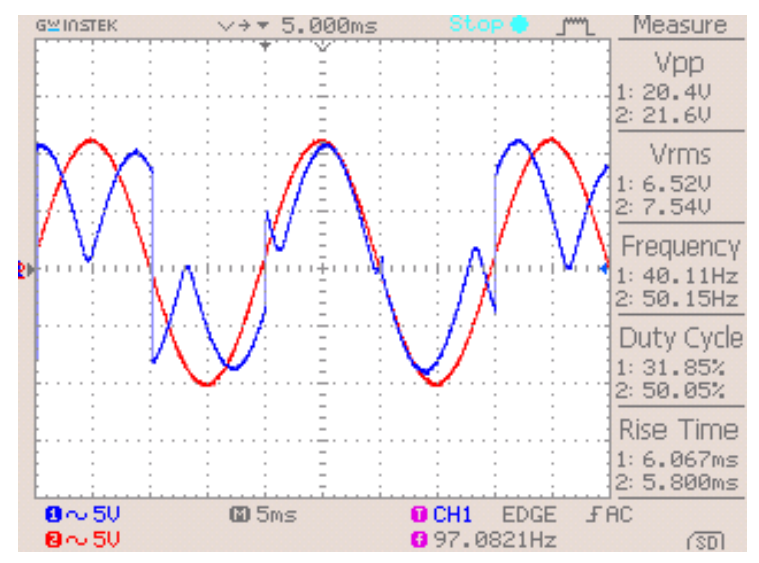

Gambar 9. Gelombang penurunan frekuensi dari $60 \mathrm{~Hz}$ menjadi $50 \mathrm{~Hz}$.

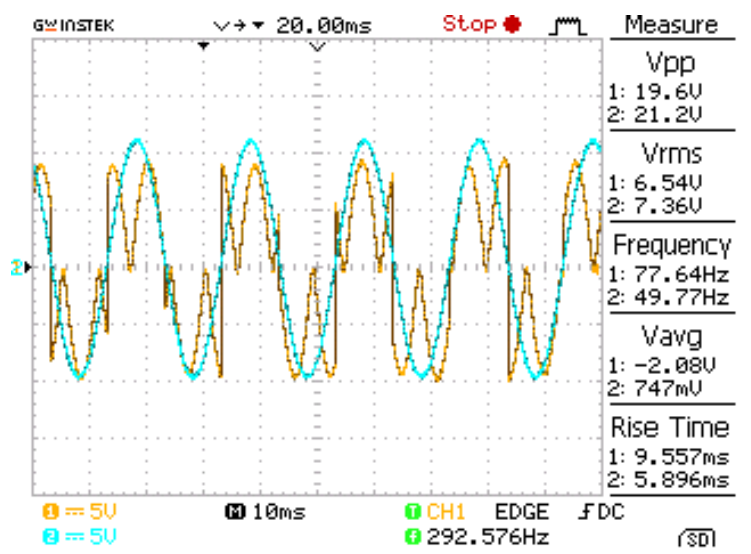

Gambar 10. Gelombang penurunan frekuensi dari $90 \mathrm{~Hz}$ menjadi $50 \mathrm{~Hz}$.

Pada rangkaian cycloconverter gelombang masukannya adalah $50 \mathrm{~Hz}$ dan akan diubah menjadi $60 \mathrm{~Hz}$ berdasakan nilai referensi frekuensi yang didapatkan dari pembangkit lama yang telah diolah oleh rangkaian pengaktifan MOSFET dan nilai Vrms keluarannya dapat diubah berdasarkan nilai referensi penyulutan tyhristor. Hasilnya dapat dilihat Gambar 11.

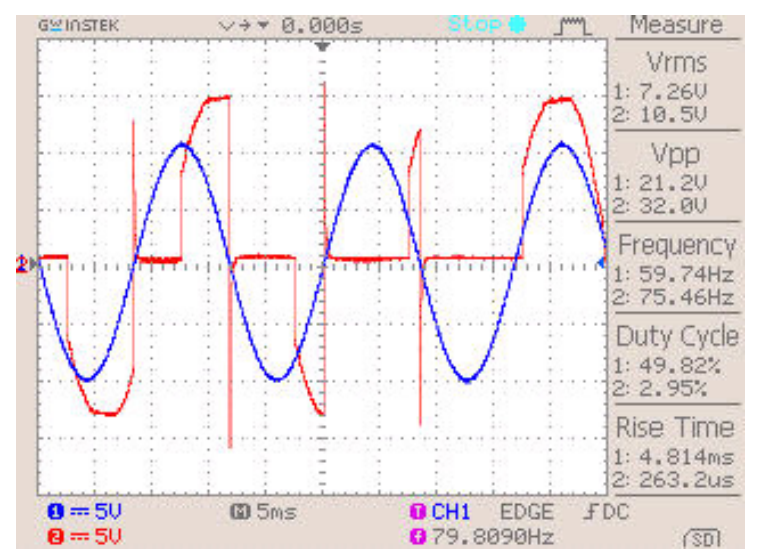

Gambar 11. Gelombang keluaran cycloconverter (merah) terhadap gelombang keluaran pembangkit lama (biru).
Dari data tersebut di atas dapat dilihat perubahan frekuensi yang terjadi. Dengan cara mengatur waktu pengaktifan MOSFET, frekuensi gelombang bisa berubah dari $50 \mathrm{~Hz}$ menjadi $60 \mathrm{~Hz}$ dan sebagainya. Waktu pengaktifan MOSFET diatur oleh sensor frekuensi (zero crossing detector) apabila sensor frekuensi mendeteksi bahwa frekuensi pada gelombang adalah $60 \mathrm{~Hz}$ maka waktu yang dibutuhkan dalam membuat frekuensi $60 \mathrm{~Hz}$ adalah:

$$
\begin{aligned}
\mathrm{f}=60 \mathrm{~Hz}=>\mathrm{T} & =1 / \mathrm{f} \\
& =1 / 60 \mathrm{~s} \\
& =16,67 \mathrm{~ms}
\end{aligned}
$$

Waktu yang dibutuhkan untuk membuat satu gelombang baru adalah $16,67 \mathrm{~ms}$. Pada rangkaian digunakan dua buah MOSFET yang aktif secara bergantian, maka untuk satu buah MOSFET waktu pengaktifannya sebesar $8,335 \mathrm{~ms}$. Selain itu dengan menggunakan bantuan sensor frekuensi dapat diketahui pula bahwa sudut fasa juga dapat disinkronkan.

Dari hasil percobaan dapat dilihat bahwa terjadi penurunan tegangan rata-rata pada gelombang keluaran. Terdapat dua penyebab penurunan nilai tegangan tersebut yaitu: rugi-rugi daya penyakelaran akibat penggunaan MOSFET dan Rumus keluaran dari gelombang penyearah dioda adalah:

$$
\text { Vout }=0,9 \text { Vin }
$$

Sehingga nilai tegangan rata-rata keluaran selalu lebih rendah dari nilai tegangan rata-rata masukannya.

Apabila fungsi dari Dioda digantikan oleh Thyristor maka nilai tegangan rata-rata gelombang keluaran akan cenderung lebih berkurang lagi sehingga untuk percobaan ini rangkaian cycloconverter tidak menggunakan Thyristor tapi menggunakan Dioda.

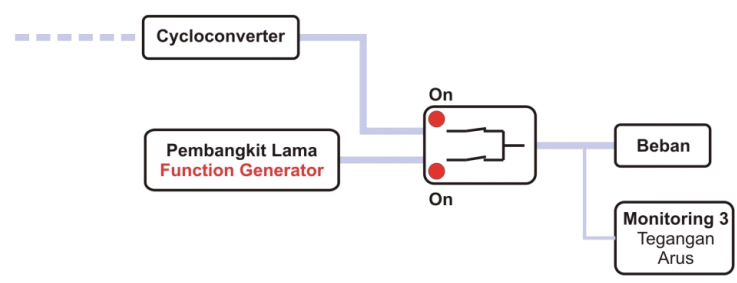

Gambar 12. Pengaturan sudut penyulutan thyristor.

Proses sinkronisasi dapat dilakukan dengan tiga proses sekuen yaitu frekuensi dari pembangkit listrik baru sama dengan frekuensi pembangkit lama, tegangan dari pembangkit listrik baru sama dengan tegangan pembangkit 
lama, dan sudut fasa dari pembangkit listrik baru sama dengan pembangkit lama sehingga sefasa. Ketika semua proses sekuen sudah terpenuhi maka koneksi antara pembangkit listrik lama dan pembangkit baru dapat dilakukan. Diagram untuk proses koneksi dapat dilihat pada gamabar 12 .

Hasil dari koneksi antara pembangkit dapat dilihat pada Gambar 13.

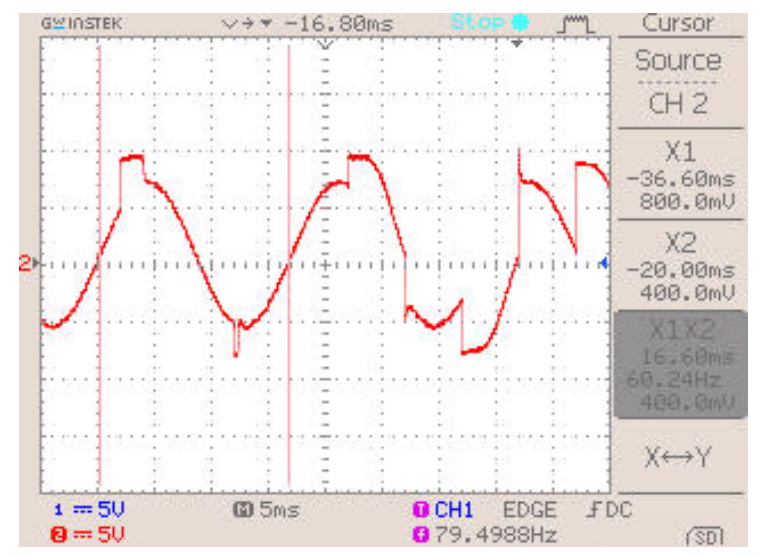

Gambar 13. Gelombang keluaran hasil koneksi antar pembangkit.

Dari Gambar 13 dapat dilihat gelombang yang dihasilkan tidak membentuk gelombang sinus sempurna, karena gelombang tersebut telah mengalami penggabungan antara gelombang yang dihasilkan oleh cycloconverter dengan gelombang dari pembangkit lama. Dapat dilihat pulsa frekuensi yang dihasilkan memiliki frekuensi yang sama dengan frekuensi pembangkit lama.

\section{KESIMPULAN DAN SARAN}

Rangkaian cycloconverter hasil modifikasi dapat menurunkan dan menaikan suatu frekuensi tertentu pada jaringan listrik menjadi frekuensi yang ingin dicapai dan menjadikan urutan fasa yang tidak sefasa menjadi sefasa dengan menggunakan bantuan sensor frekuensi (zero crossing detector) yang hasil dari pembacaan sensor tersebut menjadi titik acuan pengaktifan MOSFET.

Rangkaian cycloconverter yang dibuat pada tegangan pembangkit yang sama tidak mengakibatkan terjadinya kenaikan tegangan melainkan terjadinya kekurangan besar tegangan, hal ini disebabkan karena pada rangkaian cycloconverter ini tidak menggunakan thyristor tetapi dioda.
Dengan proses kendali sekuen pada Cycloconverter maka sinkronisasi dapat dilakukan, sehingga memungkinkan untuk menghubungkan pembangkit listrik ke jala-jala listrik.

\section{UCAPAN TERIMAKASIH}

Ucapan terimakasih disampaikan kepada Sdr Sodipta dan Sdr Yudi, alumni AE Polman Bandung angkatan tahun 2007 yang telah membantu kelancaran kegiatan penelitian ini, serta kepada proyek I-MHERE melalui program Research Grant atas biaya yang diberikan untuk kegiatan penelitian ini.

\section{Daftar Pustaka}

[1] Willis, H. L., "Power distribution planning reference book", Marcel Dekker, Inc., 2nd ed., 2004.

[2] Short, T. A., "Electric power distribution handbook," CRC Press, 2004.

[3] Lander, Cyril W., "Power electronics" (3rd ed.), London: McGraw-Hill, 1993. ISBN 0-07-707714-8.

[4] Thomas P. Hughes, "Networks of power: electrification in western society" 18801930, The Johns Hopkins University Press, Baltimore, 1983. ISBN 0-8018-2873-2.

[5] Grigsby, L. L., et al., "The electric power engineering handbook", USA: CRC Press, 2001. ISBN 0-8493-8578-4.

[6] Dorf, Richard C., The electrical engineering handbook, Boca Raton: CRC Press, 1993. ISBN 0-8493-0185-8

[7] Sistem Pengendali Elektronika Daya [Online]. Available: http://www.scribd.com/doc/31754304/Sist em-pengendali-Elektronika-Daya. diakses 4/12/2010.

[8] Kadek Fendy Sutrisna, (November 2008) Cycloconverter : $A C-A C$ Konverter Penurun Frekuensi [Online]. Available: http://konversi.wordpress.com/2008/11/20/ cyclo-converter-ac-ac-konverter-penurunfrekuensi/, diakses 4/12/2010.

[9] Anoop Mathew, [Online]. Available: http://www.anoopmathew.110mb.com/file s/ diakses 4/12/2010. 